\title{
African Stock Markets and Return Predictability
}

\author{
Gyamfi N.E ${ }^{1 *}$, Kyei K.A ${ }^{1}$, Gill R ${ }^{2}$ \\ ${ }^{1}$ University of Venda, Thohoyandou, South Africa \\ ${ }^{2}$ Department of Mathematics, UL, Louisville, USA \\ *winterblaze1707@gmail.com
}

\begin{abstract}
This article re-examines the return predictability of eight African stock markets. When returns of stocks are predictable, arbitrageurs make abnormal gains from analyzing prices. The study uses a nonparametric Generalised Spectral (GS) test in a rolling window approach. The rolling window approach tracts the periods of efficiency over time. The GS test is robust to conditional heteroscedasticity and it detects the presence of linear and nonlinear dependencies in a stationary time series. Our results support the Adaptive Market Hypothesis (AMH). This is because, indices whose returns were observed to be predictable by analyzing them in absolute form and therefore weak - form inefficient showed trends of unpredictability in a rolling window.
\end{abstract}

Keywords: Generalised Spectral Test, Martingale, Relative efficiency, rolling window, African stock markets

\section{Introduction and Literature Review}

The Efficient Market Hypothesis (EMH) postulated by Fama (1970) states that available information on a particular market is reflected in setting current security prices. This means that it is difficult to make abnormal profits by studying information on the market. The EMH was classified into three by Fama (1970) as weak-form efficiency, semi-strong form efficiency and strong form efficiency. Analysis of studies on stock return predictability on the African continent has mainly relied on using the whole sample of a particular index which seeks to find absolute efficiency. In finding absolute efficiency, the conclusion of a particular market is either weak - form efficient or weak - form inefficient when the analysis is done using past price information. This has resulted in mixed conclusions about the weak-form Efficient Market Hypothesis (EMH) on African stock markets. Studies on the weak-form type of the EMH on African stock markets that have been reported in the literature are that of Jammine \& Hawkins (1974), Affleck-Graves \& Money (1975), Dickinson \& Muragu(1994), Osei(1998), Olowe(1999), Bundoo(2000), Magnusson \& Wydick (2002), Smith et al. (2002), Appiah-Kusi \& Menyah (2003), Simons \& Laryea (2005), Jefferis \& Smith (2005), Smith (2008), Mollah \& Vitali (2011), Ntim et al. (2011b) and Gyamfi et al. (2016a, 2016b). These studies have ended with mixed conclusions. The mixed conclusions on the markets which are as a result of the absolute efficiency approach employed in the analysis are problematic because it makes the markets risky. But according to Cajueiro and Tabak (2004), stock markets are believed to become efficient with time because of the improvements in the quality of information processing and reforms on the markets, Hall and Urga (2002). Therefore drawing conclusions over a whole sample does not take into account time frames for lower or higher efficiency, Afego (2015). This work employs the relative efficiency reasoning which is consistent with the Adaptive Markets Hypothesis (AMH) of Lo $(2004,2005)$.

The AMH states that market efficiency is not an all-or-none condition but a feature that varies continuously with time. In the literature, relative market efficiency is achieved using a rolling window or time-varying approach. For example, Cajueiro and Tabak (2004) estimated Hurst exponents in each window to test for long-term linear dependence and use the median as a statistical measure when ranking the markets. Lim (2007) and Lim and Brooks (2010) used the rolling bicorrelation test statistic that focuses on nonlinear dependence, arguing that a more appropriate indicator for relative efficiency would be the percentage of time windows in which the market exhibited significant nonlinear dependence. On the African continent, studies on relative efficiency of stock markets have been few with only that of Jefferis \& Smith (2005) and Smith \& Dyakova (2014). This article therefore contributes to the extant literature on relative efficiency of African stock markets. We extend the work of Smith and Dyakova (2014) by analyzing returns of indices from eight 
African stock markets using the Generalised spectral test of Escanciano and Velasco (2006). The Generalised spectral test (GST) is a non-parametric test which does not depend on distributional assumptions. It is able to detect a wide range of linear and non-linear dependencies in conditional mean, hence having more power than other competing tests such as the automatic portmanteau Box-Pierce test and the wild-bootstrapped automatic variance ratio test (Charles et al., 2010).

Our work analyzes past prices hence we will be finding out if the markets under study are weak-form efficient or not. This is achieved if our results from using the non-parametric GST show whether a market is predictable or not. In using the GST method, a p-value is obtained. If the p-value is less than 0.05 , the market is predictable and hence weak-form inefficient else the market is weak-form efficient. If a market is predictable, arbitrageurs can study past prices and predict the future prices on the market. Therefore, the importance of this study is to find out if there were periods where the markets were efficient. The rolling window approach will let us tract the efficiency of the markets through time. The study will add on to the extant literature on market efficiency of African stock markets and also get investors well informed on the dynamics of African stock markets. The rest of the article is as follows: Section 2 describes the data; the source and the indices representing each of the eight countries. Section 3 briefly describes the Generalised spectral test of Escanciano and Velasco (2006). Section 4 presents summary statistics of the data as well as the empirical results. Section 5 discusses the results and we conclude the article in section six.

\section{Data \& Methodology}

Eight indices were selected from DataStream representing eight countries which were denominated in their respective local currency units for the sample period from $28 / 8 / 2000$ to $28 / 8 / 2015$. Table 1 is from Gyamfi, et al. (2016b).

Table 1: Countries and their corresponding stock index

\begin{tabular}{ll}
\hline Country & Representative Index \\
\hline Botswana & S\&P Botswana BMI \\
Egypt & EGX 30 \\
Kenya & NSE 20 \\
Mauritius & SE Semdex \\
Morocco & Morocco All Share (MASI) \\
Nigeria & Nigeria All Share \\
South Africa & FTSE/JSE All Share \\
Tunisia & Tunindex \\
\hline
\end{tabular}

Closing prices from these indices were transformed into returns which were calculated by $Y_{t}=\ln \left(\left(P_{t} / P_{t-1}\right)\right.$ Where $P_{t}$ and $P_{t-1}$ are the daily closing prices of the index on two consecutive trading days.

The Generalised Spectral Test: The Generalised spectral (GS) test of Escanciano and Velasco (2006) is a non-parametric test designed to detect the presence of linear and nonlinear dependencies in a stationary time series. The GS test considers dependence at all lags; it is robust to conditional heteroscedasticity and it is consistent against a class of uncorrelated non-martingale sequences. Monte-Carlo tests done by researchers such as Charles et al. (2010) to study comparison between small sample properties of other tests for martingale difference hypothesis (MDH) conclude that the GS test has better power under nonlinear dependence and have more empirical power than other tests. The GS test proceeds as followed in Todea and Lazar (2012):

Let $\left\{Y_{t}\right\}_{t=1}^{n}$ be a stationary return time series. The null hypothesis of a martingale difference sequence of the return series is tested against the alternative hypothesis using a pairwise approach.

Thus: $H_{0}: m_{j}(y)=0 ; j \geq 1$ almost surely where $m_{j}(y)=E\left[Y_{t}-\mu \mid Y_{t}-j=y\right]$ and $\mu$ is the mean against $H_{1}: P\left(m_{j}\left(Y_{t-j}\right)\right) \neq 0>0$ for some $j \geq 1$.

Let $\gamma_{j}(x)=E\left[\left(Y_{t}-\mu\right) e^{i x T_{t-j}}\right]$ be a nonlinear measure of dependence where $x \in \mathbb{R}$. 
The exponential weighting function is used to measure the conditional mean dependence in a nonlinear time series. The null hypothesis above is therefore consistent with $\gamma_{j}(x)=o$ for all $\mathrm{j} \geq 1$ almost everywhere.

Escanciano and Velasco (2006) used the generalised spectral distribution function:

$$
H(\lambda, x)=\gamma_{0}(x) \lambda+2 \sum_{j=1}^{\infty} \gamma_{j}(x)[\sin (j \pi \lambda) / j \pi]
$$

Where $\lambda \in[0,1]$. The sample estimate of $\mathrm{H}$ becomes

$$
\hat{H}(\lambda, x)=\gamma_{0}(x) \lambda+2 \sum_{j=1}^{\infty}(1-j / n)^{1 / 2} \hat{\gamma}_{j}(x) \frac{\sin (j \pi \lambda)}{j \pi}
$$

Where $(1-j / n)^{1 / 2}$

is a Sample finite correction factor, $\hat{\gamma}_{j}(x)=(n-j)^{-1} \sum_{t=1+j}^{n}\left(Y_{t}-Y^{-}{ }_{n-j}\right) e^{i x Y_{t-j}}$

And $(n-j)^{-1} \sum_{t=1+j}^{n} Y_{t}$. The generalised spectral distribution function under the null of martigale difference hypothesis $(\mathrm{MDH})$ therefore becomes $H(\lambda, x)=\gamma_{0}(x) \lambda$. The test is based on the difference between $\hat{H}(\lambda, x)$ and $\hat{H}_{0}(\lambda, x)=\gamma_{0}(x) \lambda$ as following:

$$
S_{n}(\lambda, x)=\left(\frac{n}{2}\right)^{1 / 2}\left[\hat{H}(\lambda, x)-\hat{H}_{0}(\lambda, x)\right]=\sum_{j=1}^{\infty}(1-j / n)^{1 / 2} \hat{\gamma}_{j}(x) \frac{\sqrt{2} \sin (j \pi \lambda)}{j \pi}
$$

We use the Cramer-von Mises norm in equation (4) below to evaluate the distance of $S_{n}(\lambda, x)$ to zero for all possible values of $\lambda$ and $x$

$$
D_{n}^{2}=\int_{R}^{1} \int_{0}^{1}\left|S_{n}(\lambda, x)\right|^{2} W(d x) d \lambda=\sum_{j=1}^{n-1}(n-j) \frac{1}{(j \pi)^{2}} \int_{R}|\hat{\gamma}(x)|^{2} W(d x)
$$

Where the weighing function $W($.$) satisfies some mild conditions. If the standard normal cumulative$ distribution functions is settled as weighting function, the following statistics results:

$$
D_{n}^{2}=\sum_{j=1}^{n-1} \frac{(n-j)}{(j \pi)^{2}} \sum_{t=j+1}^{n} \sum_{s=j+1}^{n}\left(Y_{t}-Y_{n-j}{ }^{-}\right)\left(Y_{s}-Y_{n-j}^{-}\right) \exp \left[-0.5\left(Y_{t-j}-Y_{s-j}\right)^{2}\right]
$$

The null hypothesis of martingale difference hypothesis is rejected when values of $D_{n}^{2}$ are large. Because the asymptotic distribution of the test depends on the data generating process in a complicated way, the authors propose implementing the test using the wild bootstrap procedure. The validity of the bootstrap procedure was proved, allowing approximating the critical values. The p-values for the test statistic $D_{n}^{2}$ are obtained by the following steps as outlined in Escanciano and Velasco (2006).

- Compute the statistics $D_{n}^{2}$ for the stationary return time series, $\left\{Y_{t}\right\}_{t=1}^{n}$

- Simulate a sequence $\left\{w_{t}\right\}_{t=1}^{n}$ of independent random variables with zero mean, unit variance and bounded support independent of the observed sequence

- Compute $\hat{\gamma}_{0}^{*}(x)=(n-j)^{-1} \sum_{t=1+j}^{n}\left(Y_{t}-Y_{n-j}^{-} \hat{\Phi}_{t-j}(x) w_{t} \quad\right.$ then $\quad S_{n}^{*} \quad$ and $\quad D_{n}^{*} 2 \quad$ where $\hat{\Phi}_{t-j}(x)=e^{i x Y_{t-j}}-(n-j) \sum_{t=j+1}^{n} e^{i x Y_{t-j}}$ 
- Repeat step 2 and 3 many times to obtain a bootstrap distribution of the test statistics.

The $\mathrm{p}$-value of the test statistics is thus estimated as the proportion of $D_{n}^{*} 2$ greater than $D_{n}^{2}$

A p-value is first computed for the first 500 observations, the first observation is then dropped and the sample rolled one point forward to re-estimate the next p-value. In this study, a window length of 500 observations lead to 3416 rolling windows for each of the return series. Also, a statistical indicator of relative efficiency proposed by Lim (2007) which determines the percentage of time windows for which a p-value is less than 0.05 is used.

\section{Empirical Results}

We first begin with preliminary analysis to determine the time series properties of the return of the indices under study. We then apply the Generalised spectral test to compute the p-values on the full sample. We divide the sample into two and compute p-values for the period from 2000 to 2007 and from 2008 to 2015 before we finally compute the p-value for each rolling window in order to observe the time variation in predictability for the indices.

Preliminary Analysis: Table 2 provides the descriptive statistics of the return series for the eight indices. It is observed that the return series are non - Gaussian. The kurtosis coefficients are large and mostly skewed negatively. The Jarque - Bera test statistic null hypothesis is rejected at the $1 \%$ level of significance. The Augmented Dickey - Fuller test shows that the return series are stationary. Table 3 reports the p-values for the generalised spectral test for the full sample and the two sub-samples.

Table 2: Descriptive Statistics for returns

\begin{tabular}{llllllll}
\hline Market & $\begin{array}{l}\text { Number } \\
\text { observations }\end{array}$ & Mean & $\begin{array}{l}\text { Std. } \\
\text { Deviation }\end{array}$ & Skewness & Kurtosis & $\begin{array}{l}\text { Jarque- } \\
\text { Bera }\end{array}$ & ADF \\
\hline Botswana & 3915 & 0.0006 & 0.0078 & 5.8172 & 124.9661 & 2572200 & -14.823 \\
Egypt & 3915 & 0.0006 & 0.0169 & -0.4309 & 10.1907 & 17084 & -14.491 \\
Kenya & 3915 & 0.0002 & 0.0093 & 0.3047 & 31.6902 & 164070 & -13.932 \\
Mauritius & 3915 & 0.0004 & 0.0067 & 0.2802 & 22.7257 & 84396 & -13.543 \\
Morocco & 3915 & 0.0003 & 0.0077 & -0.4954 & 7.1333 & 7712 & -14.117 \\
Nigeria & 3915 & 0.0003 & 0.0133 & -0.6872 & 368.4107 & 22164000 & -14.862 \\
South & 3915 & 0.0005 & 0.0121 & -0.1164 & 3.6536 & 2190.4 & -15.743 \\
Africa & & & & & & & \\
Tunisia & 3915 & 0.0003 & 0.0053 & -0.4453 & 11.2584 & 20833 & -14.500 \\
\hline
\end{tabular}

Table 3: The p-values for Generalised Spectral test

\begin{tabular}{llll}
\hline Market & Full sample & $\mathbf{2 0 0 0 - 2 0 0 7}$ & $\mathbf{2 0 0 8 - 2 0 1 5}$ \\
\hline Botswana & 0.3167 & 0.3800 & 0.0433 \\
Egypt & 0.0000 & 0.0000 & 0.0000 \\
Kenya & 0.0000 & 0.0067 & 0.0300 \\
Mauritius & 0.0000 & 0.0000 & 0.0300 \\
Morocco & 0.0000 & 0.0000 & 0.1000 \\
Nigeria & 0.9100 & 0.3133 & 0.0000 \\
South Africa & 0.5100 & 0.3933 & 0.4533 \\
Tunisia & 0.0000 & 0.0033 & 0.0200 \\
\hline
\end{tabular}


Plots of P-values using Rolling Window approach

Fig1 : Plot of p-values for Botswana and Egypt
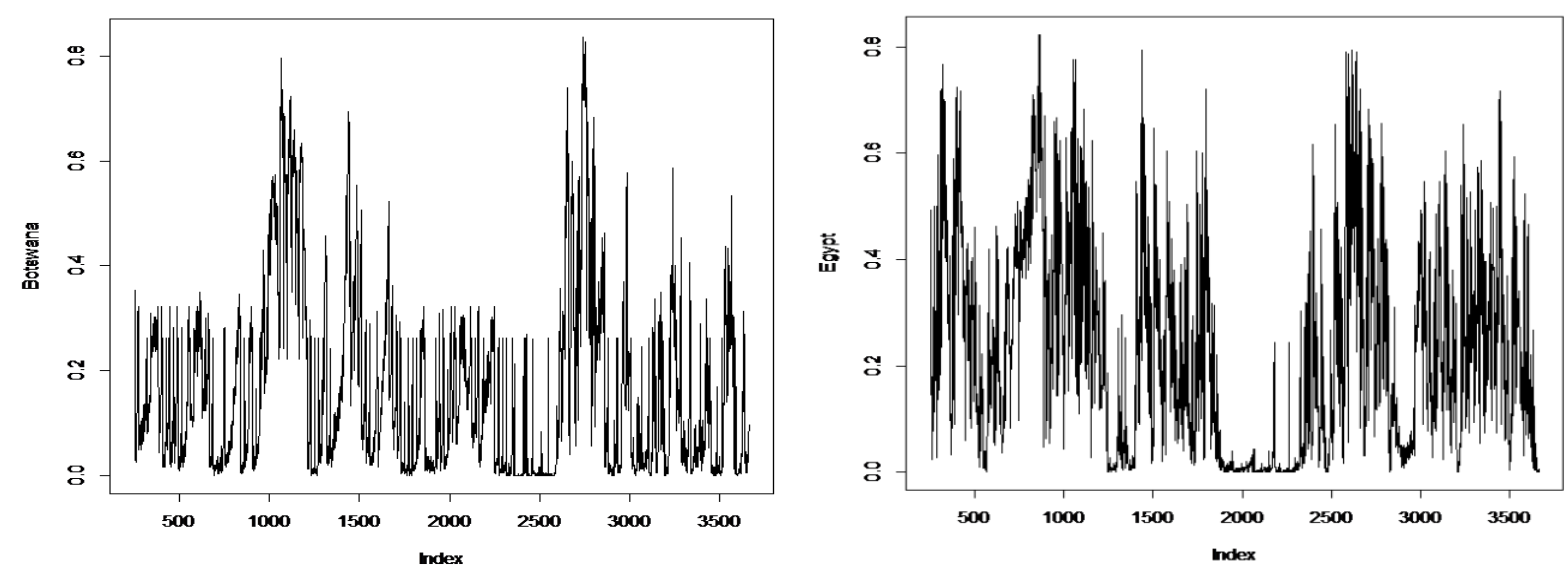

Fig 2: Plot of p-values for Kenya and Mauritius
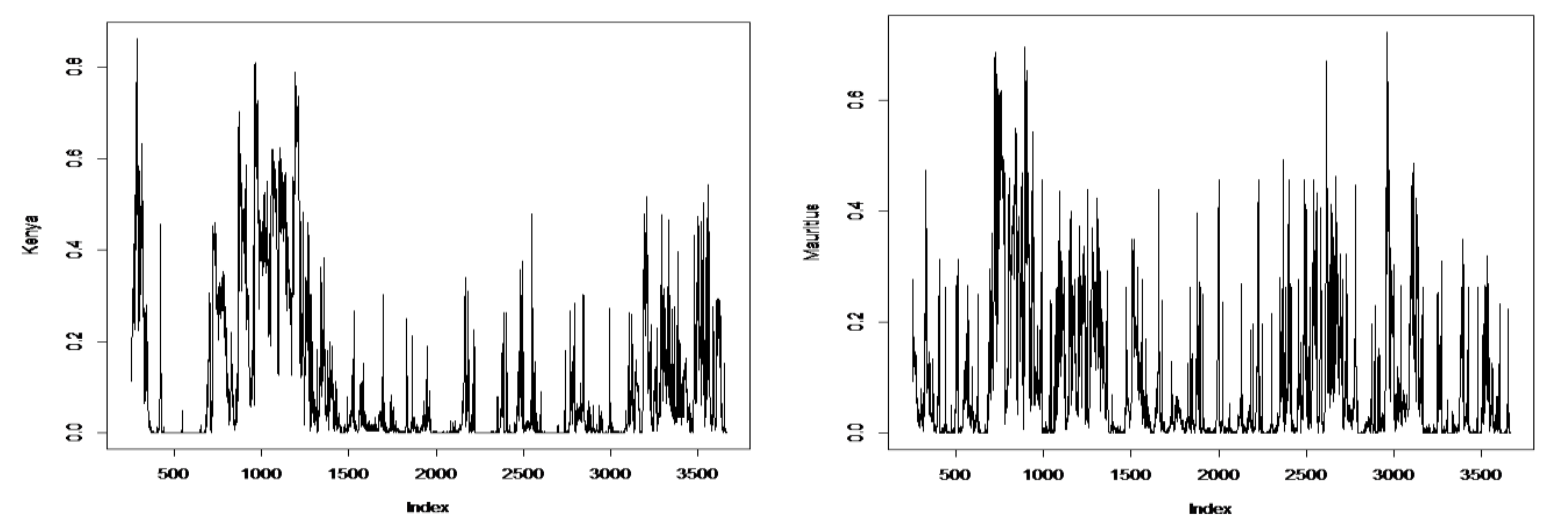

Fig 3: Plot of p-values for Morocco and Nigeria
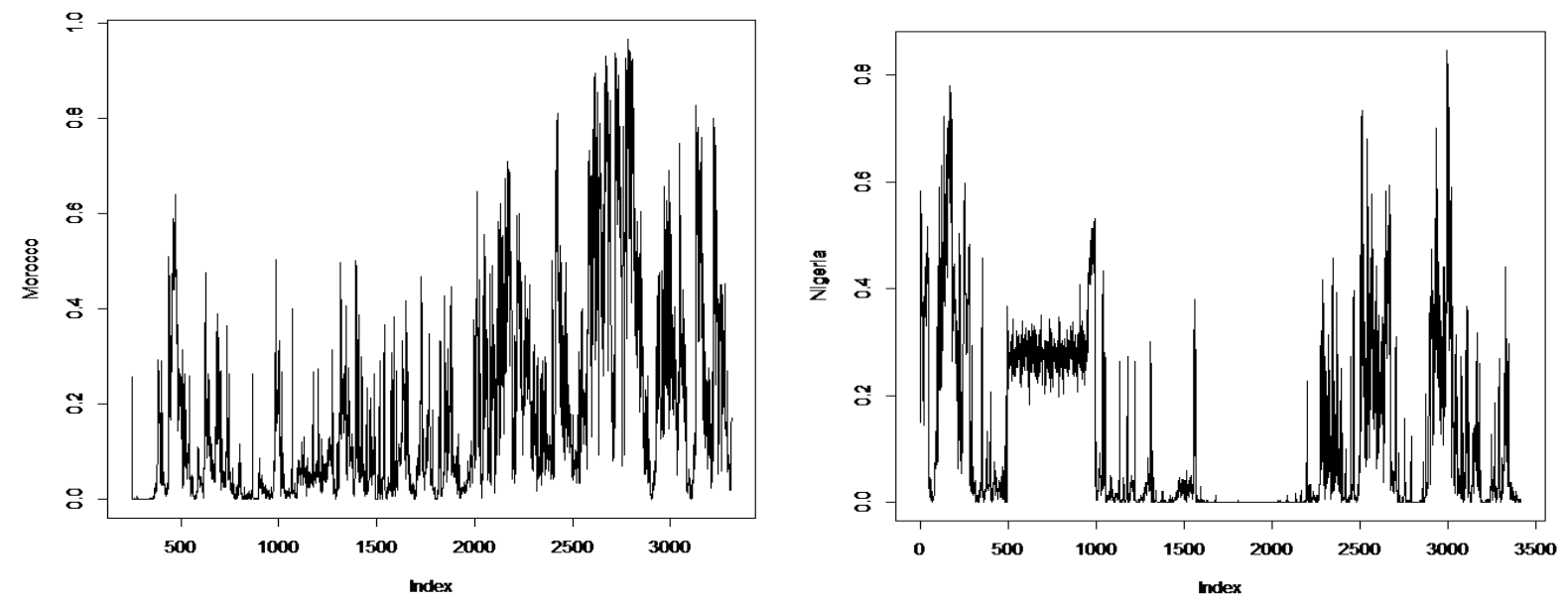
Fig4: Plot of p-values for South Africa and Tunisia
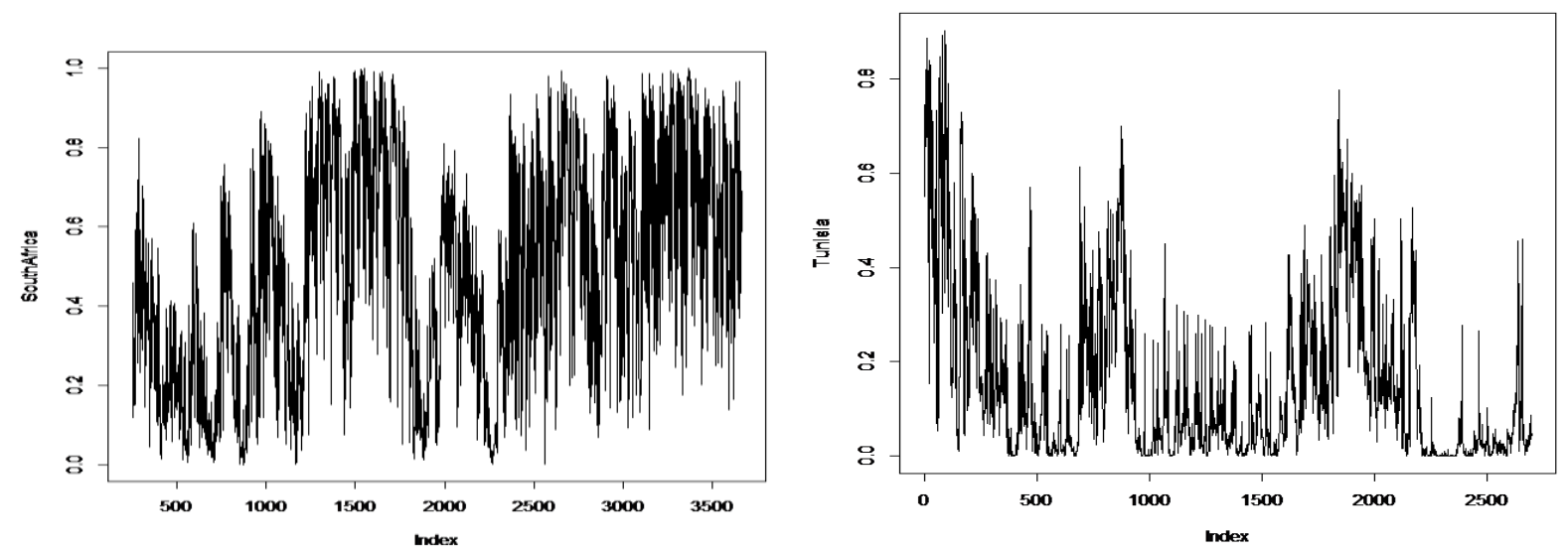

Table 4: Percentage of p-values $<0.05$

\begin{tabular}{lllll}
\hline Market & Full sample & $\mathbf{2 0 0 0 - 2 0 0 7}$ & $\mathbf{2 0 0 8 - 2 0 1 5}$ & \\
Botswana & 36.27 & 18.61 & 53.92 & \\
Egypt & 24.18 & 9.19 & 39.16 & . \\
Kenya & 61.21 & 38.70 & 83.72 & 2. \\
Mauritius & 59.66 & 38.70 & 80.62 & 3. \\
Morocco & 32.99 & 51.63 & 14.36 & 4. \\
Nigeria & 58.25 & 36.59 & 79.91 & 5. \\
South Africa & 3.48 & 4.80 & 2.17 & 6. \\
Tunisia & 40.32 & 39.91 & 40.73 & 7. \\
\hline
\end{tabular}

Discussion: We discuss the results of this work with respect to each of the countries under study. The plots of the $\mathrm{p}$ - values from the rolling window approach in Figures 1 - 4 are numerically discussed.

Botswana: It is observed in Table 3 which contains the p - values using the Generalised Spectral Test (GST) in absolute form that the full sample and the sample for the period between 2000 and 2007 are not predictable. (i.e. $0.3167>0.05)$. The sample becomes predictable for the period between 2008 and $2015(0.0433<0.05)$. The rolling window results in Table 4 establish that about $36.27 \%$ of the windows for the full sample had a p value less than 0.05 . This number decreases to $18.61 \%$ for the sample between 2000 and 2007 but increases to $53.92 \%$ for the sample between 2008 and 2015. The results show that, the stock market in Botswana was highly predictable between 2008 to 2015. This observation shows a contradiction of the position by Cajueiro and Tabak (2004b) on stock market efficiency. They posit that markets become efficient with time but our results for Botswana show otherwise. This means arbitrageurs can make abnormal returns on this market by studying past price information.

Egypt: The p - values as reported in Table 3 shows that the index is predictable. The full sample and the two subs - samples have a p - value of 0.0000 which is less than 0.05 . This makes the index weak - form inefficient, a conclusion which contradicts that of Appiah - Kusi and Menyah (2003) but conforms to the results of Simons and Laryea (2005). The results for the rolling windows show only $24.18 \%, 9.19 \%$ and $39.16 \%$ of the windows for the full sample and the sub - samples are predictable. Therefore, it will be statistically incorrect to label the whole sample as rejecting the null hypothesis of return predictability as reported in Table 3 . This conforms to the work of Smith and Dyakova (2014) who concluded that the Egyptian market is least predictable in a rolling window.

Kenya: The index is predictable and hence weak - form inefficient as evidenced by results in Table 3. More than half of the windows for the full sample have a $\mathrm{p}$-value less than 0.05 and it is more predictable for the period between 2008 and 2015 as $83.72 \%$ of the windows had a p - value less than 0.05 . This predictability conclusion contradicts the results by Dickinson and Muragu (1994) that used serial correlations and the runs test to analyze the Kenyan market for the period between 1979 to 1989. However, the return predictability 
conclusion is in conformity with the results of Jefferis and Smith (2005) and that of Smith and Dyakova (2014).

Mauritius: The index is predictable as reported in Table 3 with respect to the full sample and the two subsamples. This conforms to the results in the literature on Mauritius by Bundoo (2000) and Simons \& Laryea (2005). The full sample has almost $60 \%$ of the windows being predictable. This number goes up to $80.62 \%$ of the windows being predictable for the sub - sample between 2008 and 2015 contradicting the assertion that markets and for that matter indices become efficient with time.

Morocco: The full sample has a p - value of 0.00 in Table 3 hence predictable but the index is not predictable for the period between 2008 and 2015. About 15\% of the windows for the sample between 2008 and 2015 are predictable. This means the index is becoming efficient with time as the number of windows that are predictable reduces from $51.63 \%$ for the 2000 to 2007 period to about $15 \%$ for the period between 2008 and 2015.

Nigeria: The p - value from Table 3 shows the index is not predictable for the full sample and the period between 2000 and 2007 but becomes predictable for the period between 2008 and 2015. This shows the index is not becoming efficient with time. In absolute form, the index would have been concluded as weak form efficient. This conclusion will thus conform to Olowe (1999) and Jefferis and Smith (2005) but contradicts that of Magnusson\& Wydick (2002), Smith et al. (2002), Smith (2008) and Mollah \& Vitalli (2011). Results from the rolling window in Table 4 shows that almost $60 \%$ of the windows are predictable for the full sample and about $80 \%$ windows predictable for the period between 2008 and 2015 . These results show that Nigerian market is becoming predictable with time which contradicts Cajueiro and Tabak (2004b) but conforms to the results obtained by Smith and Dyakova (2014).

South Africa: The most weak - form efficient index of all the indices under study based on results from Table 3. It is not predictable as the $\mathrm{p}$ - values for the full sample and that of the sub - samples are greater than 0.05 . This result is in conformity with the results obtained by Affleck-Graves \& Money (1975), Magnusson \& Wydick (2002), Smith et al. (2002), Simons \& Laryea (2005), Jefferis \& Smith (2005), McMillan \& Thupayagale (2008) and Mollah \& Vitalli (2011) but not in conformity with the results of Jammie \& Hawkins (1974) and that of Smith (2008). The results from the rolling window approach in Table 4 shows that less than $4 \%$ of the windows had a p - value less than 0.05 in the full sample and the sub - samples. This makes the South African market the least predictable, a conclusion that resonates with that of Smith \& Dyakova (2014).

Tunisia: Results in Table 3 concludes that the index is predictable but the rolling window results show that less than $50 \%$ of the windows of the full sample and the sub - samples have a $\mathrm{p}$ - value less than 0.05 . We cannot therefore conclude the Tunindex is predictable as there are about $60 \%$ of periods of unpredictability. The index is thus least predictable as concluded in Smith and Dyakova (2014).

\section{Conclusion and Recommendations}

This study re-examined and extended the work of Smith and Dyakova (2014) by analyzing the return predictability of eight African stock markets. We analyzed the data using the non-parametric Generalised Spectral Test of Escanciano and Velasco (2006) in a rolling window approach. Our results favour the Adaptive Market Hypothesis (AMH) of Lo $(2004,2005)$. This is because each of the return series showed trends in the time variation of return predictability. For example, Egypt, one of the oldest markets in Africa was found to be highly predictable and therefore weak-form inefficient when the analysis was done in absolute form. The $\mathrm{p}$ values were 0.0000 for the full sample and the two subs - samples. This observation violates the assertion that markets become efficient with time as posited by Cajueiro and Tabak (2004b). However, in the rolling window approach, results for Egypt showed that it was not highly predictable as observed earlier using the full sample because it had one of the lowest percentages of the windows that had a p-value less than 0.05 after South Africa. It is thus recommended from our results that researchers must be cautious in concluding whether a market is predictable and hence weak- form inefficient. This is because investors aim to make profit and hence look out for some of this information before investing in a particular market. Therefore, the 
rolling window approach must be employed in analyzing the data to tract periods of predictability so that concrete decisions on weak-form efficiency or otherwise can be made.

\section{References}

Afego, P. (2015). Market Efficiency in Developing African Stock Markets: What do we know? The Journal of Developing Areas, 49(1), 243-266

Affleck-Graves, J. F. \& Money, A. H. (1975), A Note on the Random Walk Model and South African Share Prices. South African Journal of Economics, 43(3), 382 - 338.

Appiah-Kusi, J. \& Menyah, K. (2003), Return predictability in African Stock Markets. Review of Financial Economics, 12(3), 247 - 270.

Bundoo, S. K. (2000). The Mauritius Stock Exchange: An Assessment. Social Sciences and Humanities and Law and Management Research Journal, 3, 67 - 80.

Cajueiro, D. \& Tabak, B. (2004a). Ranking efficiency for emerging markets. Chaos, Solitons Fractals 22, 349352.

Cajueiro, D. \& Tabak, B. (2004b). The Hurst exponent over time: testing the assertion thatemerging markets are becoming more efficient. Phys. A Stat. Theor. Phys., 336(3), 521-537.

Charles, A., Darne, O. \& Kim, J. H. (2010), Small sample properties of alternative testsfor martingale difference. Economics Letters, 110, 151 - 154.

Dickinson, J. P. \& Muragu, K. (1994). Market Efficiency in Developing Countries: A CaseStudy of Nairobi Stock Exchange. Journal of Business Finance \& Accounting, 21(1), 133 -150.

Escanciano, J. C. \& Velasco, C. (2006). Generalized spectral tests for the martingale difference hypothesis. Journal of Econometrics, 134, 51 - 185.

Fama, E. (1970). Efficient Capital Markets: A Review of Theory and Empirical Work. The Journal of Finance, 25(2), 383-417.

Gyamfi, E. N., Kyei, K. A. \& Gill, R. (2016a). Long-memory in asset returns and volatility: Evidence from West Africa. Investment Management and Financial Innovations, 13(2), 24-28

Gyamfi, E. N., Kyei, K. A. \& Gill, R. (2016b). Long-memory persistence in African Stock Markets. EuroEconomica, 35(1), 83 - 91.

Hall, S. \& Urga, G. (2002). Testing for Ongoing Efficiency in the Russian Stock Market, Unpublished paper.

Jammine, A. P. \& Hawkins, D. M. (1974). The Behaviour of some Share Indices: A Statistical Analysis. South African Journal of Economics, 42(1), 43 - 55.

Jefferis, K. \& Smith, G. (2005), The Changing Efficiency of African Stock Markets. SouthAfrican Journal of Economics, 73, 54 - 67.

Lim, K. P. (2007). Ranking of market efficiency for stock markets: a nonlinear perspective. Physica A, 376, 445 $-454$.

Lim K. P. \& Brooks, R. (2010). Why do emerging stock markets experience more persistentprice deviations from a random walk over time? A country-level analysis. Macroeconomic Dynamics, 14(Suppl. 1), 3 41.

Lo, A. (2004). The Adaptive Markets Hypothesis: Market Efficiency from an Evolutionary Perspective. Journal of Portfolio Management, 30, 15 - 29.

Magnusson, M. A. \& Wydick, B. (2002). How efficient are Africa's emerging stock markets? Journal of Development Studies, 38, 141 - 156.

McMillan, D. G. \& Thupayagale, P. (2008). Efficiency of the South African equity market. Applied Financial Economics Letters, 4, 327-330.

Mollah, S. \& Vitali, F. (2011), Stock market efficiency in Africa: Evidence from RandomWalk Hypothesis, paper submitted to the South Western Finance Conference, available athttp://southwesternfinance.org/conf2011/swfa2011 submission 82.pdf.

Ntim, C. G., Opong, K. K., Danbolt, J. \& Dewotor, F. S. (2011b). Testing the weak-form efficiency in African stock markets. Managerial Finance, 37(3), 195-218.

Olowe, R. A. (1999). Weak Form Efficiency of the Nigerian Stock Market: Further Evidence. African Development Review, 11(1), 54-68.

Osei, K. A. (1998). Analysis of Factors affecting the Development of an Emerging Capital Market: The Case of the Ghana stock market, African Economic Research Consortium Research Paper 76, Nairobi, Kenya. 
Simons, D. \& Laryea, S. A. (2005), Testing the Efficiency of African Markets. Finance India, 20, 553 - 571.

Smith, G., Jefferis, K. \& Ryoo, H. J. (2002). African stock markets: Multiple variance ratiotests of random walks. Applied Financial Economics, 12, 475 - 484.

Smith, G. (2008). Liquidity and the Informational Efficiency of African Stock Markets. SouthAfrican Journal of Economics, 76(2), 161 - 175.

Smith, G. \& Dyakova, A. (2014), African Stock Markets: Efficiency and Relative Predictability. South African Journal of Economics, 82(2), 258-275.

Todea, A. \& Lazar, D. (2012). Global Crisis and Relative Efficiency: Empirical Evidence from Central and Eastern European Stock Markets. Review of Finance and Banking, 4(1), 45-53. 